\title{
Early clinical outcomes of a novel rheolytic directional thrombectomy technique for patients with iliofemoral deep vein thrombosis
}

\author{
Jörn F. Dopheide1, Tim Sebastian¹, Rolf P. Engelberger², Axel Haine1 , and Nils Kucher \\ Clinic for Angiology, Swiss Cardiovascular Center, Inselspital, Bern University Hospital, University of Bern, Bern, Switzerland \\ Division of Angiology, Cantonal Hospital Fribourg, Fribourg, Switzerland \\ UniversitätsSpital Zürich, Zürich, Switzerland
}

\begin{abstract}
Summary: Background: Rheolytic thrombectomy (RT) for acute iliofemoral deep vein thrombosis (DVT) with first-generation techniques is often incomplete and adjunctive conventional catheter-directed thrombolysis (CDT) is required in more than half of patients to achieve venous patency. Patients and methods: From the prospective Bern Venous Stent Registry, we investigated rates of primary treatment success, primary patency, and post-thrombotic syndrome (PTS) from 40 consecutive patients (mean age $51 \pm 19$ years, $45 \%$ women) with acute iliofemoral DVT, treated with a novel directional RT technology and stent placement. Overall, 24 patients were treated for native-vessel iliofemoral DVT (11 with single-session RT, 13 with bailout RT after failed CDT) and 16 for iliofemoral stent thrombosis. Pulse-spray thrombolysis (r-tPA $10 \mathrm{mg}$ ) was performed in 29 (73\%) patients. The mean follow-up duration was $193 \pm 132$ days (minimum 90 days). Results: Overall, primary treatment success of RT was 95\%; only two patients required adjunctive CDT to restore patency. In 24 patients with native-vessel DVT, six-month primary patency was $92 \%$ (95\% Cl 75-99\%), and 23 patients (96\%) were free from the PTS according to the Villalta score. In 16 patients with stent thrombosis, six-month primary patency was $63 \%(95 \% \mathrm{Cl} 35-85 \%)$ and $50 \%$ were free from PTS. Except for transient macroscopic haemoglobinuria in all patients, no other side effects were recorded. Conclusions: In patients with iliofemoral DVT of native or stented vessels, RT followed by stent placement appears to be effective and safe. The novel technique enables single-session DVT treatment in the majority of patients without the need for prolonged CDT.
\end{abstract}

Keywords: Iliofemoral deep vein thrombosis, post-thrombotic syndrome, rheolytic thrombectomy, catheter-directed thrombolysis, AngioJet ZelanteDVT

\section{Introduction}

Acute iliofemoral deep vein thrombosis (DVT) is a major cause for morbidity, as approximately half of the patients managed conservatively with anticoagulation therapy and compression stockings develop the post-thrombotic syndrome (PTS) [1-4]. The residual thrombus load correlates with the probability of a future PTS $[5,6]$. The degree of the PTS correlates with impairment of quality of life $[7,8]$.

As compared to conservative therapy, catheter-directed thrombolysis (CDT) is associated with greater venous patency and reduced risk of PTS at two years [9]. International consensus guidelines recommend CDT with provisional stent placement of the underlying venous outflow obstruction for selected patients with acute iliofemoral DVT [10, 11]. However, CDT with provisional stent placement is complex because it involves catheter placement in a first session, prolonged monitoring in the intermediate care unit during the administration of local thrombolysis, and venography with provisional stent placement in a second session.

In recent years, a trend emerged to complete the DVT revascularization and stent placement procedure in a single session. Rheolytic thrombectomy (RT) uses the Venturi-Bernoulli effect (negative pressure induced by fast flowing saline jets) and enables single-session DVT therapy [12]. Rheolytic thrombectomy can be combined with adjunctive local administration of a high-pressure thrombolysis spray (PowerPuls ${ }^{\circledR}$ ) to facilitate thrombus removal. In the Peripheral Use of AngioJet Rheolytic Thrombectomy with a Variety of Catheter Lengths (PEARL) study of 329 DVT patients, RT with a first-generation system (AngioJet ${ }^{\circledR} 6$ F, Boston Scientific, Maple Grove, MN, USA) was effective and safe [13]. However, $61 \%$ of the PEARL 
patients required adjunctive CDT to restore venous patency. The Angiojet ZelanteDVT ${ }^{\circledR}$ catheter (Boston Scientific, Maple Grove, MN, USA) is a novel 8-French RT system specifically designed for single-session treatment of acute iliofemoral DVT.

The aim of the present study was to investigate patency rates and early clinical outcomes of patients with acute iliofemoral DVT treated with the Angiojet ZelanteDVT ${ }^{\circledR}$ system.

\section{Patients and methods}

\section{Study design}

The current analysis was derived from the Bern Venous Stent Registry, an ongoing study that consecutively enrols patients who received venous stents at the University Clinic of Angiology in Bern, Switzerland, since 1 January 2008. From this registry we included all patients with least 90 days of follow-up, who underwent AngioJet ZelanteDVT for acute iliofemoral DVT or iliofemoral venous stent thrombosis since market introduction in December 2015. Exclusion criteria for registry enrolment are the inability to provide informed consent, age below 18 years, or estimated life expectancy $<3$ months.

The registry and participant consent form were approved by the Swiss Ethics Committee on research involving humans. The study is registered on the National Institutes of Health website (ClinicalTrials.gov; identifier NCT02433054).

For all enrolled patients, baseline demographic information (age, gender, weight, height, indication), comorbid conditions (concomitant pulmonary embolism, active cancer or treatment, thrombophilia, hypertension), risk factors (smoking, hormonal therapy, previous DVT, immobility, recent surgery/trauma, May-Thurner compression, obesity), and anticoagulant/antiplatelet therapy were recorded. Procedural data included type, diameter, length, and site of implanted stents. Venograms were used to analyse thrombus extension and primary treatment success.

For this analysis we predefined three patient groups:

1. primary single-session RT for iliofemoral DVT of native vessels,

2. bail-out RT after incomplete or failed CDT for iliofemoral DVT of native vessels,

3. primary single-session RT of DVT caused by iliofemoral venous stent thrombosis.

\section{Study device}

The Angiojet ZelanteDVT ${ }^{\circ}$ (Boston Scientific, Marlborough, MA, USA) catheter is a novel RT device which has been specially designed for single-session treatment of iliofemoral DVT (Figure 1).

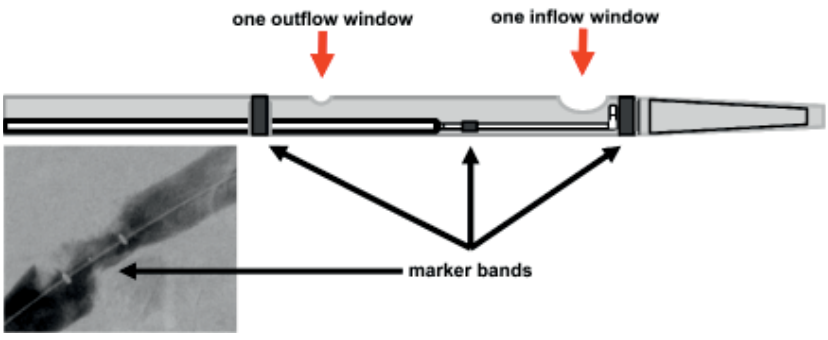

Figure 1. AngioJet ZelanteDVT ${ }^{\circledR}$ catheter.

Schematic drawing of the tip of the 8-French AngioJet ZelanteDVT ${ }^{\circledR}$ catheter (Boston Scientific, Maple Grove, MN, USA). It is an isovolumetric, directional, hydrodynamic thrombectomy device using accelerated reversed fluid, which runs through the inside of the catheter and provides a strong $-600 \mathrm{mmHg}$ suction (Venturi) effect at the catheter tip. The treatment segment with one larger proximal suction window and one smaller distal outflow window (arrows) can be identified under fluoroscopy through two marker bands. Between the marker bands is an eccentric middle marker, indicating the (opposite) direction of the inflow and outflow windows.

\section{Procedures}

Iliofemoral DVT was objectively confirmed by duplex ultrasound or contrast-enhanced computed tomography. All patients were initially treated with intravenous unfractionated heparin, adjusted to target and partial thromboplastin time corresponding to therapeutic heparin levels was activated (equivalent to 0.3 to $0.7 \mathrm{U} / \mathrm{mL}$ by factor $\mathrm{Xa}$ inhibition). In patients with thrombus extension into the popliteal veins, initial CDT was mainly performed as a first thrombus removal strategy. Following popliteal access with a 10-French sheath, RT (AngioJet ZelanteDVT ${ }^{\circ}$ ) was performed using two thrombectomy passes of the thrombotic occlusion by advancing the device by 2-3 millimetre per second. Each device activation run lasted no longer than 30 seconds with breaks of 30 seconds in between the runs to avoid arrhythmia. During the thrombectomy procedure, the rotation hub at the catheter shaft was rotated by 270 degrees back and forth to accomplish circumferential thrombus removal. If RT was incomplete, defined as absence of flow or residual thrombus with near complete vessel occlusion, an intraclot injection of $10 \mathrm{mg}$ of r-tPA (total injected volume 30 millilitres) using the PowerPulse ${ }^{\circledR}$ technique was performed. After 20 Minutes dwell time, another two thrombectomy passes were performed as described above, not exceeding a total device activation time of 300 seconds. Diagnosis of an iliac vein compression syndrome or of residual post-thrombotic obstruction was established after successful thrombus removal by digital subtraction venography in two orthogonal views or by intravascular ultrasound if venography was equivocal. Stenting was performed in the presence of a venous stenosis $>50 \%$ by intravascular ultrasound or venography or in the presence of collateral flow, or in the absence of flow [14].

Depending on the affected venous segment and the presence or absence of a compression syndrome, the following stents were used: for the inferior vena cava Sinus$\mathrm{XL}^{\circledR}$ stent, for compressed iliac veins Sinus-Obliquus ${ }^{\circledR}$ May Thurner stent, for post-thrombotic iliac or common femo- 
ral veins Sinus-XL Flex ${ }^{\circledast}$ stent, and for the deep femoral vein Sinus-SuperFlex ${ }^{\circledast}$ stent (Optimed, Ettlingen, Germany). Stent diameters were $20-24 \mathrm{~mm}$ for the inferior vena cava, $14-16 \mathrm{~mm}$ for the iliac veins, $14 \mathrm{~mm}$ for the common femoral vein, and $12 \mathrm{~mm}$ for the deep femoral vein.

Following endovascular therapy, oral anticoagulation therapy was initiated. Patients received either vitamin $\mathrm{K}$ antagonists or direct oral anticoagulants (rivaroxaban, apixaban, or dabigatran).

\section{Clinical follow-up}

Clinical follow-up assessments with duplex sonography were performed in all patients at the vascular outpatient clinic by vascular specialists at the first postinterventional day, at three, six, and 12 months. At each visit, signs and symptoms of post-thrombotic syndrome, including all points of the Villalta score [15] and the revised venous clinical severity score [16] were systematically examined by vascular specialists. Each stented venous segment was examined by ultrasound for (1) the presence or absence of thrombotic changes (thickening of the venous wall, intraluminal webs, intraluminal material) and (2) flow patterns in treated segments to determine if they were modulated by the cardiac cycle, spontaneously modulated with respiration, or modulated with deep inspiration. Peak flow velocities $[\mathrm{cm} / \mathrm{sec}]$ were recorded from the common femoral vein.

\section{Definition of outcomes}

Primary treatment success was defined as antegrade flow and maximal luminal stenosis of $30 \%$ assessed on the final procedural venography and evidence of a spontaneous Doppler signal in the treated vein segment [17]. Primary patency rate was defined as the percentage of patients with primary treatment success and without the occurrence of either thrombosis of the treated segment or a reintervention to maintain patency of the treated segment. Restenosis in the treated venous segment was defined by ultrasound as a luminal obstruction of $>50 \%$ of the venous cross-sectional area in B-mode or deterioration of the Doppler flow pattern from the first postinterventional day to the follow-up ultrasound study. This included an increase of the peak flow velocity to $>1 \mathrm{~m} / \mathrm{s}$ or a loss of respiratory modulation of flow.

\section{Statistical analyses}

Continuous baseline and outcome data were presented as mean \pm standard deviations and were compared between the three groups, using one-way analysis of variance and Dunn's multiple comparison tests. Categorical baseline and outcome data were analysed between the groups using the chi-square test. Kaplan-Meier survival analysis was used to estimate patency rates, which were reported with the $95 \%$ confidence interval. A log rank test was used to compare primary patency rates between patients with iliofemoral DVT and patients with iliofemoral venous stent thrombosis. A p $<0.05$ indicated statistical significance. For data management and statistical analysis, we used the Prism $^{\circledast}$ V5.0f statistical software package $\left(\mathrm{GraphPad}^{\circledast}\right.$, San Diego, CA, USA).

\section{Results}

\section{Baseline characteristics}

Overall, 40 patients (mean age $51 \pm 19$ years; 18 women) were treated with directional RT between December 2015 and March 2017. During the observation period, five patients with iliofemoral DVT were treated conservatively. Baseline characteristics were similar in the groups except for a history of previous DVT and hormonal therapy (Table I). Overall, 24 patients (60\%) had acute iliofemoral DVT of native veins of which 11 were treated in a single session and 13 in a bail-out session after incomplete CDT with r-tPA $20 \mathrm{mg}$ over 15 hours. Sixteen patients (40\%) presented with iliofemoral venous stent thrombosis; the index diagnosis and reason for stent implantation was PTS in 11 cases (69\%) and acute iliofemoral DVT in five cases (31\%).

\section{Procedural data}

Figure 2 shows an example of venograms at baseline, after $\mathrm{RT}$, and at completion of the procedure for the three groups. Primary treatment success after RT was achieved in 38 patients (95\%). In two patients, adjunctive CDT was necessary to achieve venous patency. None of the 40 patients received an IVC filter. Balloon angioplasty and stent placement was performed in all patients (mean $3.5 \pm 3.2$ stents) (Table II). Among the 16 patients with stent thrombosis, 15 (94\%) patients had post-thrombotic venographic changes of the leg inflow veins (femoral and deep femoral veins) at the time of the index procedure.

There were no periprocedural adverse events, such as arrhythmia, bleeding complications or symptomatic pulmonary embolism. Transient macroscopic haemoglobinuria during the first 24 hours after intervention was recorded in all patients. The majority of patients received oral anticoagulation therapy with either direct oral anticoagulants $[\mathrm{n}=31(78 \%)]$ or vitamin $\mathrm{K}$ antagonists $[\mathrm{n}=8$ (20\%)]. One patient with active cancer received low molecular weight heparin. Duration of oral anticoagulation therapy was distributed as following: for a limited period of three months $[\mathrm{n}=11(28 \%)]$, six months $[\mathrm{n}=3(7 \%)]$, and 12 months $[\mathrm{n}=1(2 \%)]$; and for an indefinite period $[\mathrm{n}=25(63 \%)]$. 
Table I. Baseline characteristics ${ }^{a}$.

\begin{tabular}{|c|c|c|c|c|}
\hline & \multirow[t]{2}{*}{ Overall $(n=40)$} & \multicolumn{2}{|c|}{ Iliofemoral DVT $(n=24)$} & \multirow[t]{2}{*}{ Stent thrombosis $(n=16)$} \\
\hline & & Single session $(n=11)$ & Bail out $(n=13)$ & \\
\hline \multicolumn{5}{|l|}{ Demographics } \\
\hline Age, y & $50.5 \pm 19.5$ & $58.8 \pm 19.0$ & $47.9 \pm 18.9$ & $46.8 \pm 19.7$ \\
\hline Women & $18(45)$ & $5(45)$ & $7(54)$ & $6(38)$ \\
\hline Body mass index $\left(\mathrm{kg} / \mathrm{m}^{2}\right)$ & $26.2 \pm 6.0$ & $26.9 \pm 5.2$ & $27.0 \pm 3.5$ & $25.0 \pm 8.0$ \\
\hline \multicolumn{5}{|l|}{ Venous pathology } \\
\hline DVT symptoms $<14$ days & $28(70)$ & $8(73)$ & $11(85)$ & $9(56)$ \\
\hline May-Thurner compression & $12(30)$ & $5(45)$ & $3(23)$ & $4(25)$ \\
\hline Atypical iliofemoral compression & $7(18)$ & $2(18)$ & $4(31)$ & $1(6)$ \\
\hline \multicolumn{5}{|l|}{ Risk factors and comorbidities } \\
\hline Previous DVT & $19(48)$ & $3(27)$ & $2(15)$ & $14(88)$ \\
\hline Hypertension & $10(25)$ & $4(36)$ & $4(31)$ & $2(13)$ \\
\hline Immobilization $^{\mathrm{b}}$ & $8(20)$ & $3(27)$ & $3(23)$ & $2(13)$ \\
\hline Obesity $^{\circ}$ & $10(25)$ & $2(18)$ & $4(31)$ & $4(25)$ \\
\hline Concomitant pulmonary embolism & $7(18)$ & $2(18)$ & $3(23)$ & $2(13)$ \\
\hline Hormonal therapy ${ }^{d}$ & $7(18)$ & 0 & $5(38)$ & $2(13)$ \\
\hline Surgery and/or trauma ${ }^{e}$ & $6(15)$ & $2(18)$ & $2(15)$ & $2(13)$ \\
\hline Smoking & $8(20)$ & $1(9)$ & $1(8)$ & $6(38)$ \\
\hline Active cancer or treatment ${ }^{\dagger}$ & $6(15)$ & $3(27)$ & $2(15)$ & 1 (6) \\
\hline Known thrombophilia & $3(8)$ & 0 & 0 & $3(19)$ \\
\hline \multicolumn{5}{|l|}{ Thrombus extension } \\
\hline Inferior vena cava & $10(25)$ & $2(18)$ & $2(15)$ & $6(38)$ \\
\hline Common iliac vein & $38(95)$ & $11(100)$ & $13(100)$ & $14(88)$ \\
\hline External iliac vein & $40(100)$ & $11(100)$ & $13(100)$ & $16(100)$ \\
\hline Common femoral vein & $40(100)$ & $11(100)$ & $13(100)$ & $16(100)$ \\
\hline Femoral vein & $30(75)$ & $6(55)$ & $11(85)$ & $13(81)$ \\
\hline Popliteal vein & $12(30)$ & $1(9)$ & $7(54)$ & $4(25)$ \\
\hline
\end{tabular}

a: Continuous data are presented as the mean \pm standard deviation, categorical data are given as numbers with percentages; b: within the previous three months; c: defined as body mass index $>30 \mathrm{~kg} / \mathrm{m}^{2}$; d:oestrogens, tamoxifen or substitute; e: within the previous four weeks; f: within the previous six months.

\section{Clinical outcome during follow-up}

The mean follow-up duration was $193 \pm 132$ days (Table II). For the 24 patients with iliofemoral DVT of native vessels, the primary patency rate was $92 \%$ [95\% CI 75-99\%] at 180 days (Figure 3). There was one female patient with metastatic bladder cancer who had right-sided iliac stent thrombosis at day 165 , due to tumour progression with compression of the inferior vena cava and iliac veins. She underwent successful stent reconstruction of the inferior vena cava and iliac veins.
For the 16 patients with stent thrombosis, the primary patency rate was $63 \%$ [95\% CI 35-85\%] at 180 days (Figure 3). Six patients with an index diagnosis of PTS had symptomatic complete stent rethrombosis, of whom two had early rethrombosis within 30 days. Among the six patients, reintervention was attempted in three, but not successfully.

Among the seven patients who developed symptomatic stent thrombosis at follow up, six ( $86 \%$ ) had post-thrombotic venographic changes of the femoral leg inflow veins at the index procedure. Among the 33 patients with patent stents at the latest follow-up, only nine ( $27 \%$ ) had post-thrombotic 


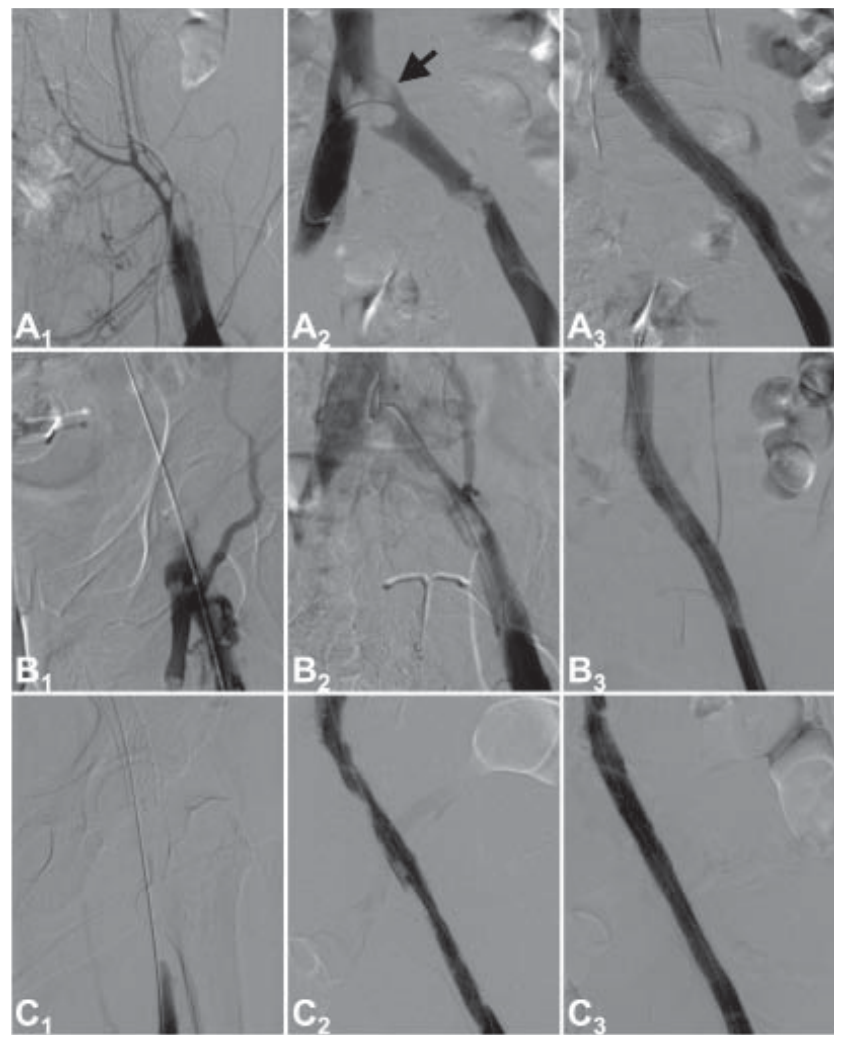

Figure 2. Digital subtraction venograms.

$A_{1}$ : Baseline venogram from a patient with acute descending iliofemoral thrombosis and typical compression of the left common iliac vein; $A_{2}$ : near complete thrombus removal after single session rheolytic thrombectomy and PowerPuls ${ }^{\circledR}$ thrombolysis ( $r$-tPA $10 \mathrm{mg}$ ); $A_{3}$ : final venographic result after stent placement in common iliac vein (Sinus Obliquus ${ }^{\circledR}$, Optimed, Germany); $B_{1}$ : venogram after failed catheter-directed thrombolysis (20 mg r-tPA over 15 hours) of a patient with acute descending iliofemoral thrombosis and May-Thurner compression; $\mathrm{B}_{2}$ : near complete thrombus removal after bailout rheolytic thrombectomy and PowerPuls ${ }^{\circledR}$ thrombolysis ( $r$-tPA $10 \mathrm{mg}$ ); $\mathrm{B}_{3}$ : final venographic result after stent placement in common iliac vein (Sinus Obliquus ${ }^{\circledR}$, Optimed, Germany); $\mathrm{C}_{1}$ : baseline venogram from a patient with acute thrombosis of an iliac vein stent; $\mathrm{C}_{2}$ : near complete thrombus removal after rheolytic thrombectomy and PowerPuls ${ }^{\circledR}$ thrombolysis ( $r$-tPA $10 \mathrm{mg}$ ); $\mathrm{C}_{3}$ : final venographic result after high-pressure balloon angioplasty of the stent.

venographic changes of the femoral leg inflow veins at the index procedure $(\mathrm{p}=<0.001)$. Among the 40 patients, there were no cases of asymptomatic venous restenosis.

Overall, the Villalta score at six months was $3.87 \pm 5.04$; 30 patients $(75 \%)$ were free from PTS with a Villalta score of $<5$ points (Table II). Among the 24 patients with iliofemoral DVT, 23 (96\%) remained free from the PTS at six months with a Villalta score of $<5$ points. Among the 16 patients with venous stent thrombosis, seven (44\%) were free from PTS at six months.

\section{Discussion}

We report the first early clinical results of a novel directional RT technique for the treatment of iliofemoral DVT. Directional RT using the AngioJet ZelanteDVT ${ }^{\circledR}$ system was effective to restore patency in combination with balloon angioplasty and venous stent placement in patients with iliofemoral DVT of native or stented vessels. PowerPuls ${ }^{\circledR}$ thrombolysis was performed in $73 \%$ patients and only $5 \%$ required adjunctive CDT to achieve venous patency. Except for transient haemoglobinuria, no periprocedural complications occurred.

In the 24 patients with acute iliofemoral DVT of native vessels, six-month primary patency was $92 \%$ and only one patient developed PTS. In patients with iliofemoral venous stent thrombosis, six-month primary patency was $63 \%$, and $56 \%$ of the patients remained free from PTS. The main reason for the less favourable patency rate in patients with iliofemoral venous stent thrombosis was likely an impaired venous stent inflow because almost all patients had post-thrombotic femoral veins at the index procedure. Despite lower patency rates, interventions for venous stent thrombosis should be considered because a permanently obstructed deep venous system may be associated with impaired quality of life and invalidity, leading to substantial disease-related costs $[18,19]$.

The novel directional RT technique was specifically designed for thrombus removal in large veins. In contrast to first-generation RT systems, features of the novel technique include (1) a larger catheter lumen ( $8 \mathrm{~F}$ instead of $6 \mathrm{~F}),(2)$ modifications at the treatment segment with one larger proximal suction window and one smaller distal outflow window, and (3) a rotational hub to accomplish directional thrombus removal (see Figure 1). The novel RT technique provides a strong $-600 \mathrm{mmHg}$ suction (Venturi-) effect at the catheter tip which is likely the reason for the observed primary treatment success without the need for adjunctive prolonged CDT in all but two patients. This clearly is an improvement when comparing our results to the results of the PEARL study, in which $61 \%$ of the patients treated by the first-generation $\mathrm{RT}$ technique required adjunctive CDT to restore venous patency [13].

There is an ongoing debate whether an early revascularization strategy is superior to anticoagulation therapy exclusively for the reduction of PTS in patients with acute iliofemoral DVT [20]. First results from the Acute venous Thrombosis: Thrombus Removal with Adjunctive Catheter-directed Thrombolysis randomized (ATTRACT) trial [21], which compared an early revascularization strategy to just anticoagulation therapy in 692 patients with proximal DVT, were presented at the congress of the Society of Interventional Radiology (SIR) in March 2017 [22]. Unfortunately, almost half of the ATTRACT patients had femoropopliteal DVT without involvement of the iliac veins; several thrombus removal strategies were allowed and only $30 \%$ of the patients had stent placement. The ATTRACT study failed to show that an early revascularization strategy was superior to just anticoagulation with similar overall PTS rates at two years of follow-up.

Currently, there is no evidence from randomized trials that RT is more effective than conventional CDT. It re- 
Table II. Procedural and clinical outcome data ${ }^{a}$.

\begin{tabular}{|c|c|c|c|c|c|}
\hline & \multirow[t]{2}{*}{ Overall $(n=40)$} & \multicolumn{2}{|c|}{ Iliofemoral DVT $(n=24)$} & \multicolumn{2}{|c|}{ Stent thrombosis $(n=16)$} \\
\hline & & Single session $(n=11)$ & Bail out $(n=13)$ & & \\
\hline \multicolumn{6}{|l|}{ Follow-up } \\
\hline Mean follow-up, days & $193 \pm 132$ & $184 \pm 93$ & $220 \pm 129$ & $179 \pm 160$ & 0.65 \\
\hline Villalta score ${ }^{b}$ & $3.9 \pm 5.0$ & $2.3 \pm 2.4$ & $1.1 \pm 1.2$ & $6.1 \pm 6.2$ & 0.01 \\
\hline No PTS (<5 points) & $31(78)$ & $10(91)$ & $13(100)$ & $8(50)$ & $<0.01$ \\
\hline rVCSS points $^{c}$ & $4.2 \pm 5.2$ & $3.6 \pm 4.8$ & $1.5 \pm 1.4$ & $6.1 \pm 6.2$ & 0.04 \\
\hline Direct oral anticoagulants & $30(75)$ & $9(82)$ & $12(92)$ & $9(56)$ & 0.07 \\
\hline Vitamin $\mathrm{K}$ antagonists & $9(23)$ & $2(18)$ & $1(8)$ & $6(38)$ & 0.15 \\
\hline Clopidogrel $^{d}$ & $10(25)$ & $2(18)$ & $2(15)$ & $6(38)$ & 0.57 \\
\hline \multicolumn{6}{|l|}{ Procedural } \\
\hline Implanted stents & $3.5 \pm 3.2$ & $2.1 \pm 2.2$ & $2.0 \pm 2.3$ & $5.7 \pm 3.2$ & $<0.001$ \\
\hline Stent length [mm] & $241 \pm 192$ & $236 \pm 227$ & $185 \pm 138$ & $290 \pm 202$ & 0.18 \\
\hline PowerPuls $®$ & $29(73)$ & $7(64)$ & $7(54)$ & $15(94)$ & 0.04 \\
\hline Peak flow velocitye (cm/sec) & $27.7 \pm 15.6$ & $31.6 \pm 20.5$ & $30.7 \pm 14.4$ & $22.5 \pm 11.9$ & 0.28 \\
\hline \multicolumn{6}{|l|}{ Stent localization } \\
\hline Inferior vena cava & $9(18)$ & $2(18)$ & $2(15)$ & $5(31)$ & 0.55 \\
\hline Common iliac vein & $38(95)$ & $11(100)$ & $13(100)$ & $14(88)$ & 0.21 \\
\hline External iliac vein & $36(90)$ & $11(100)$ & $11(92)$ & $14(88)$ & 0.42 \\
\hline Common femoral vein & $25(63)$ & $5(45)$ & $5(22)$ & $15(94)$ & $<0.01$ \\
\hline Deep Femoral vein & $4(10)$ & 0 & 0 & $4(25)$ & 0.04 \\
\hline
\end{tabular}

a: Continuous data are presented as the mean \pm standard deviation, categorical data are given as numbers with percentages; b: at last follow-up; c: revised venous clinical severity score at last follow-up; $d$ : for the initial three months after intervention; e: by Doppler ultrasound in the common femoral vein after completion of the procedure; PTS: post-thrombotic syndrome.

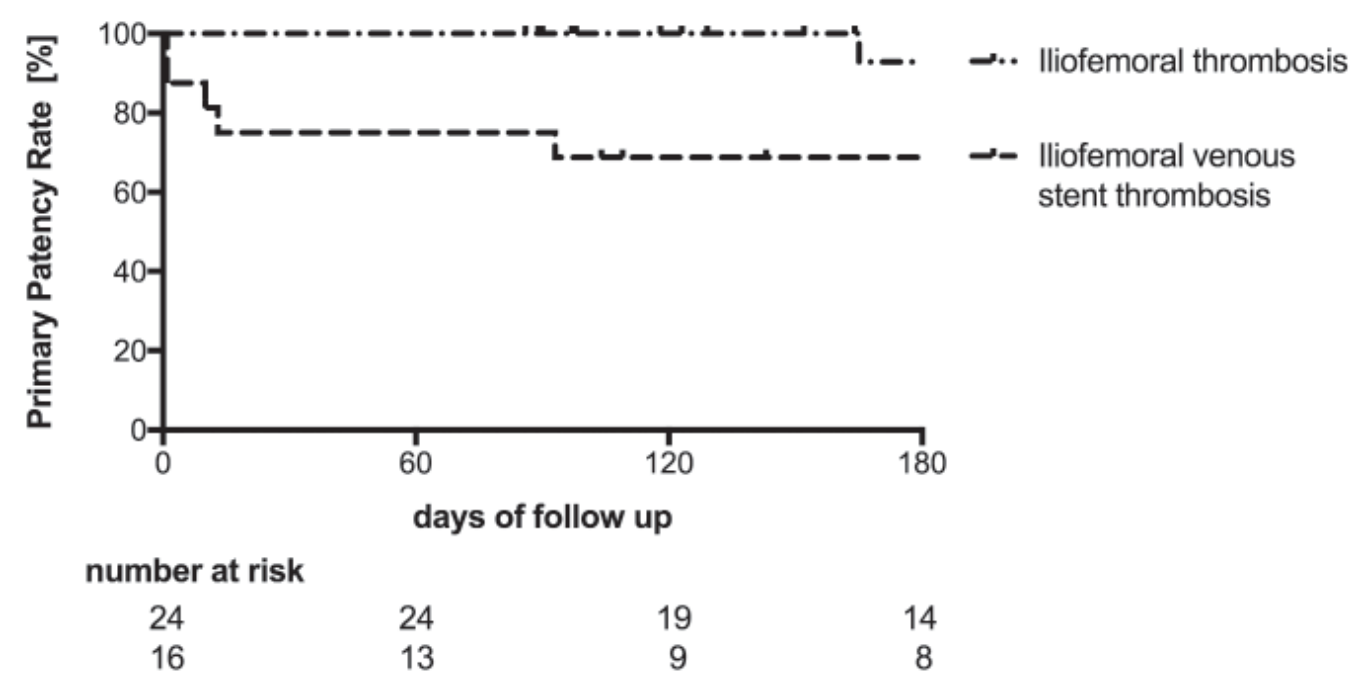

Figure 3. Primary patency. Kaplan-Meier estimates through 180 days of primary patency rates for 40 patients with iliofemoral DVT treated with directional rheolytic thrombectomy. 
mains unclear whether a single-session strategy of this novel thrombectomy technique is effective and safe in patients with extensive DVT involving the popliteal and lower leg veins. Advantages of the novel RT technique include thrombus removal and provisional stent placement in a single session, without the need for prolonged CDT, admission to the intermediate care unit or second look venography. In contrast, CDT always requires a staged intervention with catheter placement, prolonged CDT in a monitor unit, and second or third look venography with provisional stent placement.

\section{Limitations and conclusions}

Our study is limited by the relatively low number of study participants and short follow-ups. Nevertheless, our first clinical results suggest that primary treatment success and early clinical outcomes with this novel RT technique are favourable for patients with iliofemoral DVT. Overall, RT was effective to restore patency in combination with provisional PowerPuls ${ }^{\circledR}$ thrombolysis, balloon angioplasty, and venous stent placement. The novel technique enables single-session DVT treatment in the majority of patients without the need for prolonged catheter-directed thrombolysis. Future studies should investigate the long-term efficacy and safety of this promising technique in large cohorts of patients with acute iliofemoral DVT.

\section{References}

1. Stain M, Schonauer V, Minar E, et al. The post-thrombotic syndrome: risk factors and impact on the course of thrombotic disease. J Thromb Haemost. 2005;3: 2671-6.

2. Day ISCfWT. Thrombosis: a major contributor to the global disease burden. J Thromb Haemost. 2014;12:1580-90.

3. Roumen-Klappe EM, den Heijer M, Janssen MC, van der Vleuten $\mathrm{C}$, Thien $\mathrm{T}$ and Wollersheim $\mathrm{H}$. The post-thrombotic syndrome: incidence and prognostic value of non-invasive venous examinations in a six-year follow-up study. Thromb. Haemost. 2005;94:825-30.

4. Kahn SR, Shrier I, Julian JA, et al. Determinants and time course of the postthrombotic syndrome after acute deep venous thrombosis. Ann Intern Med. 2008;149:698-707.

5. Comerota AJ, Grewal N, Martinez JT, et al. Postthrombotic morbidity correlates with residual thrombus following catheterdirected thrombolysis for iliofemoral deep vein thrombosis. J Vasc Surg. 2012;55:768-73.

6. Grewal NK, Martinez JT, Andrews L, Comerota AJ. Quantity of clot lysed after catheter-directed thrombolysis for iliofemoral deep venous thrombosis correlates with postthrombotic morbidity. J Vasc Surg. 2010;51:1209-14.

7. Kahn SR, Hirsch A and Shrier I. Effect of postthrombotic syndrome on health-related quality of life after deep venous thrombosis. Arch Intern Med. 2002;162:1144-8.

8. Kahn SR, Shbaklo H, Lamping DL, et al. Determinants of health-related quality of life during the 2 years following deep vein thrombosis. J Thromb Haemost. 2008;6:1105-12.

9. Enden T, Haig Y, Klow NE, et al. Long-term outcome after additional catheter-directed thrombolysis versus standard treatment for acute iliofemoral deep vein thrombosis (the CaVenT study): a randomised controlled trial. Lancet. 2012; 379:31-8.

10. Kearon C, Akl EA, Ornelas J, et al. Antithrombotic Therapy for VTE Disease: CHEST Guideline and Expert Panel Report. Chest. 2016;149:315-52.

11. Kahn SR, Comerota AJ, Cushman M, et al. The postthrombotic syndrome: evidence-based prevention, diagnosis, and treatment strategies: a scientific statement from the American Heart Association. Circulation. 2014;130:1636-61.

12. A. L. Baert MK, K. Sartor. Vascular Interventional Radiology: Angioplasty, Stenting, Thrombolysis and Thrombectomy. In: Cowling MG, (ed.). 2006, 66.

13. Garcia MJ, Lookstein R, Malhotra R, et al. Endovascular Management of Deep Vein Thrombosis with Rheolytic Thrombectomy: Final Report of the Prospective Multicenter PEARL (Peripheral Use of AngioJet Rheolytic Thrombectomy with a Variety of Catheter Lengths) Registry. J Vasc Interv Radiol. 2015;26:777-85.

14. Engelberger RP, Fahrni J, Willenberg T, et al. Fixed low-dose ultrasound-assisted catheter-directed thrombolysis followed by routine stenting of residual stenosis for acute ilio-femoral deep-vein thrombosis. Thromb. Haemost. 2014;111:1153-60.

15. Villalta S, Bagatella P, Piccioli A, Lensing A, Prins M and Prandoni P. Assessment of validity and reproducibility of a clinical scale for the post-thrombotic syndrome. Haemostasis. 1994; $24: 158 a$

16. Vasquez MA, Rabe E, McLafferty RB, et al. Revision of the venous clinical severity score: venous outcomes consensus statement: special communication of the American Venous Forum Ad Hoc Outcomes Working Group. J Vasc Surg. 2010; 52:1387-96.

17. Vedantham S, Grassi CJ, Ferral H, et al. Reporting standards for endovascular treatment of lower extremity deep vein thrombosis. J Vasc Interv Radiol. 2006;17:417-34.

18. MacDougall DA, Feliu AL, Boccuzzi SJ, Lin J. Economic burden of deep-vein thrombosis, pulmonary embolism, and postthrombotic syndrome. Am J Health Syst Pharm. 2006;63:5-15.

19. Guanella R, Ducruet T, Johri M, et al. Economic burden and cost determinants of deep vein thrombosis during 2 years following diagnosis: a prospective evaluation. J Thromb Haemost. 2011; 9:2397-405.

20. Sharifi M, Mehdipour M, Bay C, Smith G, Sharifi J. Endovenous therapy for deep venous thrombosis: the TORPEDO trial. Catheter Cardiovasc Interv. 2010;76:316-25.

21. Vedantham S, Goldhaber SZ, Kahn SR, et al. Rationale and design of the ATTRACT Study: A multicenter randomized trial to evaluate pharmacomechanical catheter-directed thrombolysis for the prevention of postthrombotic syndrome in patients with proximal deep vein thrombosis. Am Heart J. 2013;165:523-30.e3.

22. Vedantham S. ATTRACT Trial Results Society of Interventional Radiology (SIR). Washington, D.C.2017

Submitted: 13.08.2017

Accepted after revision: 07.09.2017

Conflicts of interests:

Nils Kucher has received speaker and consulting honoraria from Boston Scientific and Optimed.

Published online: 05.10.2017

\section{Correspondence address}

Nils Kucher, MD

Angiologie

UniversitätsSpital Zürich

Rämistrasse 100

8091 Zürich

Switzerland

kuchernils@yahoo.com 